\title{
EMJ
}

\section{An evaluation of an educational intervention to reduce inappropriate cannulation and improve cannulation technique by paramedics}

A N Siriwardena, M Iqbal, S Banerjee, A Spaight and J Stephenson

Emerg. Med. J. 2009;26;831-836

doi:10.1136/emj.2008.071415

Updated information and services can be found at:

http://emj.bmj.com/cgi/content/full/26/11/831

These include:

References This article cites 20 articles, 4 of which can be accessed free at:

http://emj.bmj.com/cgi/content/full/26/11/831\#BIBL

Rapid responses You can respond to this article at:

http://emj.bmj.com/cgi/eletter-submit/26/11/831

Email alerting Receive free email alerts when new articles cite this article - sign up in the box at service the top right corner of the article

Topic collections Articles on similar topics can be found in the following collections

Clinical diagnostic tests (18450 articles)

Radiology (14593 articles)

Resuscitation (2454 articles)

Pain (neurology) (29842 articles)

Notes

To order reprints of this article go to:

http://journals.bmj.com/cgi/reprintform

To subscribe to Emergency Medicine Journal go to:

http://journals.bmj.com/subscriptions/ 


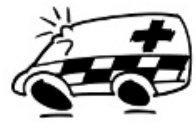

${ }^{1}$ Faculty of Health, Life \& Social Science, University of Lincoln, Brayford Pool, Lincoln, LN6 7TS, UK; ${ }^{2}$ East Midlands Ambulance Service NHS Trust, Lincolnshire Divisional Headquarters, Cross $\mathrm{O}^{\prime} \mathrm{Cliff}$ Court, Bracebridge Health, Lincoln, LN4 2HL, UK

Correspondence to: Professor A Niroshan Siriwardena, Faculty of Health, Life \& Social Sciences, University of Lincoln, Brayford Pool, Lincoln LN6 7TS, UK;

nsiriwardena@lincoln.ac.uk

Accepted 23 March 2009

\title{
An evaluation of an educational intervention to reduce inappropriate cannulation and improve cannulation technique by paramedics
}

\author{
A N Siriwardena, ${ }^{1,2}$ M Iqbal, ${ }^{2}$ S Banerjee, ${ }^{1}$ A Spaight, ${ }^{2}$ J Stephenson ${ }^{2}$
}

\begin{abstract}
Background: Intravenous cannulation enables administration of fluids or drugs by paramedics in prehospital settings. Inappropriate use and poor technique carry risks for patients, including pain and infection. We aimed to investigate the effect of an educational intervention designed to reduce the rate of inappropriate cannulation and to improve cannulation technique.
\end{abstract}

Method: We used a non-randomised control group design, comparing two counties in the East Midlands (UK) as intervention and control areas. The educational intervention was based on Joint Royal Colleges Ambulance Liaison Committee guidance and delivered to paramedic team leaders who cascaded it to their teams. We analysed rates of inappropriate cannulation before and after the intervention using routine clinical data. We also assessed overall cannulation rates before and after the intervention. A sample of paramedics was assessed post-intervention on cannulation technique with a "model" arm using a predesigned checklist.

Results: There was a non-significant reduction in inappropriate (no intravenous fluids or drugs given) cannulation rates in the intervention area $(1.0 \%$ to $0 \%)$ compared with the control area (2.5\% to $2.6 \%)$. There was a significant $(p<0.001)$ reduction in cannulation rates in the intervention area $(9.1 \%$ to $6.5 \%$; OR $0.7,95 \%$ $\mathrm{Cl} 0.48$ to 1.03$)$ compared with an increase in the control area (13.8\% to $19.1 \%$; OR $1.47,95 \% \mathrm{Cl} 1.15$ to 1.90$)$, a significant difference $(p<0.001)$. Paramedics in the intervention area were significantly more likely to use correct hand-washing techniques post-intervention (74.5\% vs. $14.9 \% ; p<0.001)$.

Conclusion: The educational intervention was effective in bringing about changes leading to enhanced quality and safety in some aspects of prehospital cannulation.

Peripheral intravenous (IV) cannulation is a common and important intervention in the prehospital setting. ${ }^{1}$ Overuse, underuse, misuse and poor technique of cannulation are all associated with potential risks. Prevention of healthcare-associated infections is currently a major concern for the National Health Service. Thus, the rate, appropriateness and technique of prehospital cannulation have become an important issue.

Cannulation is undertaken for a range of reasons, including administration of IV medication, analgesia or fluids; to take blood samples; or as a precaution against being unable to place an IV line at a later stage. Paramedics are trained to consider various factors in deciding whether to place an IV cannula, including mechanism of injury or chief medical complaint, medical history, age, vital signs, and time and distance to hospital. ${ }^{1}$ Practitioners trained to paramedic level and beyond are increasingly being used by services to provide front-line care, and, possibly linked to this increase in trained paramedics, there is a perception that the numbers of patients cannulated in the prehospital setting has increased over the years.

However, the use of this technique varies widely between paramedics or ambulance sites, even when the condition of the patient is similar. ${ }^{2}$ Although cannulation can provide necessary and clinically important vascular access, inappropriate use may cause unnecessary pain and distress and, in some cases, put patients at risk for phlebitis, catheter-related obstruction and infection. ${ }^{3}$ Cannulation may also delay transport to hospital $1^{4}$ by 1-2 minutes and poses a small risk of needle stick injury to paramedics. Although increased risk of infection or phlebitis has not been demonstrated for prehospital cannulation in recent studies, ${ }^{56}$ it was associated with emergency department compared with in-hospital cannulation insertion in one study. ${ }^{7}$ Thus, the appropriateness of cannulation has become an important issue as its use has become widespread.

A study of out-of-hospital IV cannulation by the London Ambulance Service in 2000 found that 4\% of all patients (24000 patients a year) were cannulated. ${ }^{2}$ In a sample of these cases from 1995 to $1996,17 \%$ of IV placements were judged by a specialist review panel to have been inappropriate, and wide variations in rates of IV placement between individual paramedics were found to exist. ${ }^{1}$

In an analysis of 8866 patients transported to the ED by ambulance in the Lincolnshire Division of East Midlands Ambulance Service (EMAS) in September 2006, paramedics cannulated $14.2 \%$ of patients transported by emergency ambulance. Cannulation rates varied considerably by ambulance station, with a mean rate of $13.4 \%$ (range $5.8 \%$ to $19.0 \%$ ). ${ }^{8}$ To assess whether cannulation was performed appropriately, clinical conditions were classified at the outset according to whether they warranted cannulation, did not warrant cannulation, or there was uncertainty as to the need for cannulation. Other conditions for appropriate cannulation, such as IV drug administration, consciousness level (Glasgow Coma Scale score $<8$ ), systolic blood pressure (<90 $\mathrm{mm} \mathrm{Hg}$ ), respiratory rate $(<10$ breaths per minute) and haemorrhage, were combined with clinical indication to determine whether cannulation was indicated. Criteria of appropriateness and method of analysis 
were agreed upon at the outset and based on the previous study by London Ambulance Service. ${ }^{9}$ Other variables including patient age, sex, hypoglycaemia and ambulance station were investigated as predictors of variation in rates of cannulation. It was estimated that $15.6 \%$ of cannulations could potentially have been avoided. Intravenous drug or fluid administration was the strongest predictor of cannulation.

Literature concerning prehospital cannulation is scarce, with very few published studies. In hospital settings, system changes such as the introduction of specially trained IV teams have been shown to reduce rates of infection and inflammation associated with peripheral cannulae. ${ }^{10}$

The aim of this evaluation was to investigate the effect of an educational intervention designed to increase appropriateness and technique of prehospital cannulation by paramedics.

\section{METHODS}

\section{Evaluation design}

We used a non-randomised control group (before and after) design for the evaluation (fig 1). ${ }^{11} 12$ The primary hypothesis was that after an educational intervention carried out to improve the appropriateness and technique of cannulation, there would be an increase in appropriate cannulation and an improvement in observed cannulation technique. The primary outcome was the rate of appropriate cannulation. This was operationalised as the rate of cannulation, where drugs or IV fluids were recorded as having been given, using data from routine clinical records. Secondary outcomes included overall cannulation rate (from routine clinical records) and observed cannulation technique (see below). The outcomes were measured from at least 2 months before and 2 months after the intervention took place to allow time for the education delivered to the paramedic team leaders (PTLs) to be cascaded to paramedics in their teams and for change in practice to occur.

\section{Setting}

EMAS NHS Trust provides emergency unscheduled care and patient transport services for the six counties of Derbyshire, Leicestershire, Lincolnshire, Northamptonshire, Nottinghamshire and Rutland. EMAS delivers its service through 3000 staff at $>70$ locations, with two control rooms at Nottingham and Lincoln, and by responding to over 500000 emergency calls every year.

\section{Participants}

Two geographical areas of EMAS were involved in the evaluation, with Nottinghamshire as the intervention site and Lincolnshire as the comparison site. All paramedics in these areas, 80 in Nottinghamshire and 243 in Lincolnshire, were involved in the evaluation.

\section{Intervention}

The educational intervention was based on national Joint Royal Colleges Ambulance Liaison Committee ${ }^{13}$ guidance and was delivered by clinical educators to PTLs. It was planned that the educational intervention would initially be delivered to PTLs in the intervention site (Nottinghamshire), who would subsequently cascade this to paramedics in their teams within a 2week period. If the study proved the intervention to be successful, a similar intervention was planned for delivery in other sites of EMAS.

The educational intervention in Nottinghamshire was conducted by a paramedic educator, who delivered the training as a local workshop to all PTLs between 21 February and 11 March 2008. To deliver the intervention, the tutor attended all PTL

Figure 1 Study flow diagram.

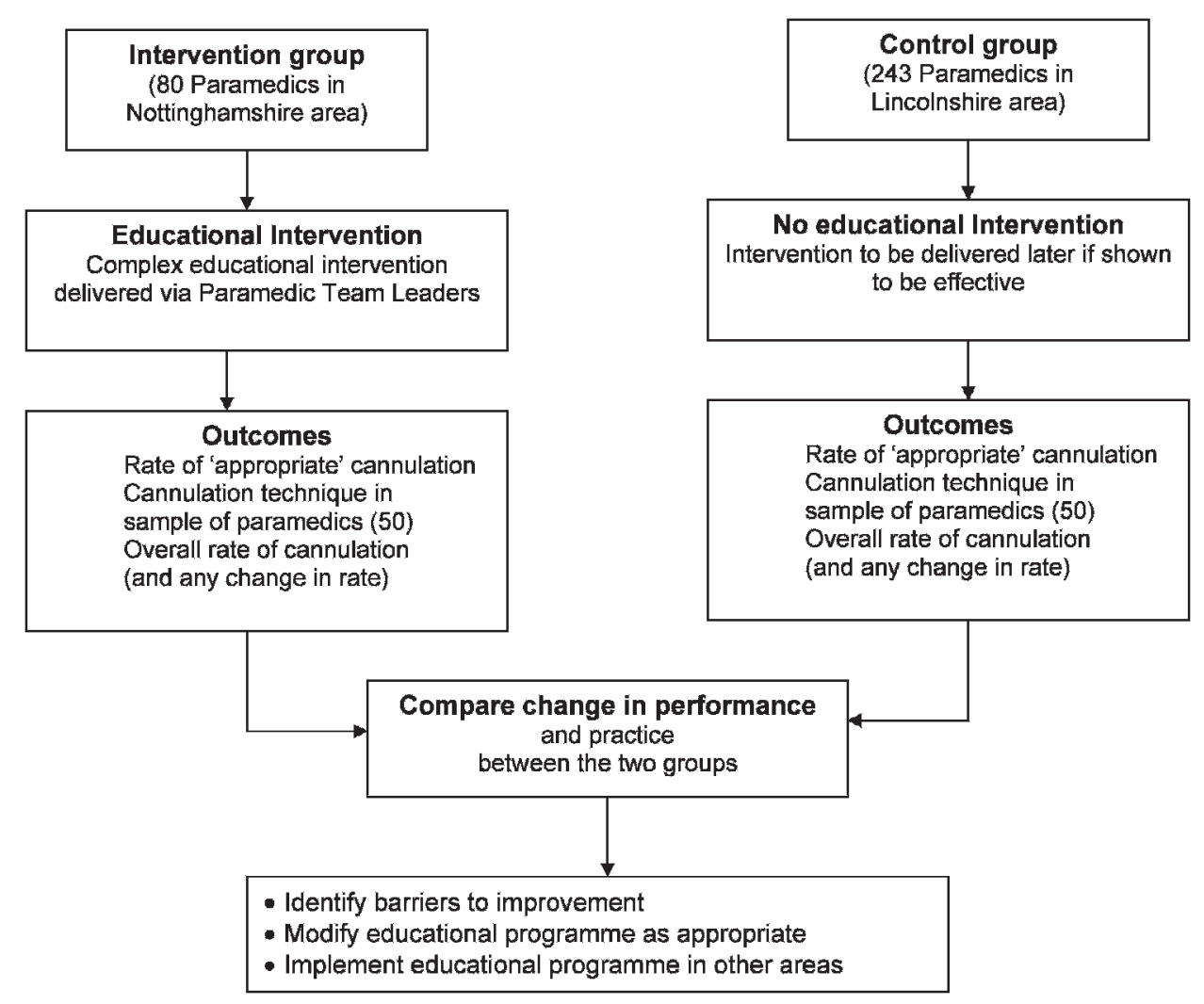


meetings, which often took place in the evenings. The PTLs then cascaded the education to paramedics within their own team over the next 2 weeks.

The educational intervention/workshop was designed to address the following learning outcomes:

- to increase appropriate and reduce unnecessary cannulation; that is, a cannula should be inserted only if

- the patient needs fluid replacement,

- the patient needs IV medication,

- the patient's condition requires it;

- to improve cannulation technique, with particular attention to prevention of sepsis;

- to cascade education to paramedics ${ }^{10-12}$ within their team.

A PowerPoint presentation was issued to each PTL, followed up with an electronic copy by email, to support educational delivery to their teams. Each PTL was issued with a pack containing the following: attendance register; presentation handout; IV cannulation guidance; no-touch procedure for IV cannulation and guidance on aseptic technique, hand hygiene procedure and gloves use; and an observation of cannulation checklist. An evaluation questionnaire was distributed to participants immediately after the training to assist in evaluating the effectiveness of the workshop.

\section{Sample size estimations}

A previous audit showed that in 1 month, paramedics cannulated $14.6 \%$ of patients. Sample size calculation with a two-sided $5 \%$ significance level and $95 \%$ power showed that to detect an odds ratio of 0.63 (risk ratio 0.67 ) in the intervention group (ie, a reduction in overall cannulation rate from $15 \%$ to $10 \%), 1450$ patients would be needed (725 cases and 725 controls).

A pragmatic approach was taken for the observation exercise to assess cannulation technique in the intervention and control sites. In both sites, 50 paramedics were selected from staff delivering patients to A\&E departments and/or from ambulance station sites during shift change over.

\section{Data collection}

The evaluation used routinely collected data from EMAS clinical records or patient report forms. All patient report forms for a period of 1 month were selected, 2 months before (February 2008) and 2 months after (June 2008) the educational intervention. Data were extracted for analysis on whether the patient was cannulated and whether IV drugs or fluids were administered. "Inappropriate cannulation" was defined as cannulation when no IV drugs or fluids were recorded as having been administered.

\section{Observation of cannulation technique}

Fifty paramedics in the intervention and comparison areas were observed by education specialists cannulating a "model" arm in an ambulance at ED sites or at the station. A checklist was used to assess cannulation/aseptic technique, which included questions on indications for cannulation and observations on cannulation technique performed on the model arm, including precannulation preparation, aseptic technique, cannulation site selection, insertion technique and procedure for finishing up.

A memo from the operation manager was circulated to all paramedics and other front-line staff to assist and encourage prospective participants. This also assured staff that those who participated would not be identified in reports.
Data were verified on receipt of data collection forms/ checklist and questionnaires. All analyses were performed with SPSS V.14. ${ }^{14}$

The evaluation did not involve any additional or nonstandard treatment of patients. The intervention emphasised that patients who needed cannulation were not denied this intervention. All data from clinical records, questionnaires and observation were anonymised. The study was approved as an evaluation by Lincolnshire Health and Social Care Steering Group.

\section{RESULTS}

Data were analysed using logistic regression to test for both main and interaction effects between predictor variables. The first regression model included site (intervention vs control), timing of testing (pre-intervention vs post-intervention) and interaction between site and timing of testing as predictor variables and overall cannulation rates as the outcome variable. The second regression model included site (intervention vs control), timing of testing (pre-intervention vs post-intervention) and interaction between site and timing of testing as predictor variables and inappropriate cannulation rates as the outcome variable.

\section{Inappropriate cannulation}

There was a reduction in inappropriate (no IV fluids or drugs given) cannulation rates in the intervention area $(1.0 \%$ to $0 \%$ ) compared with the control area (2.5\% to $2.6 \%)$. Logistic regression of the final model for inappropriate cannulation showed that site $\left(e^{B}=0.00, B=15.78, S E B=1467.74, p=0.99\right)$, timing of testing $\left(e^{B}=0.00, B=33.30, S E B=2935.48, p=0.99\right)$ and interaction between site and timing of testing $\left(e^{B}=0.00\right.$, $B=-0.67, S E B=58.71, p=0.99$ ) were not significant in predicting inappropriate cannulation (table 1).

\section{Overall cannulation rate}

The results of the logistic regression revealed that the model for overall cannulation rate was significant $(p<0.001)$. The final model revealed that site $\left(e^{B}=0.54, B=0.27, S E B=0.36\right.$, $p=0.46)$ was not a significant variable, but timing of testing (before or after intervention; $\mathrm{e}^{\mathrm{B}}=11.73, \mathrm{~B}=1.88, \mathrm{SE} \mathrm{B}=0.55$, $\mathrm{p}<0.001)$ and interaction between site and timing of testing $\left(e^{\mathrm{B}}=10.15, \mathrm{~B}=-0.03, \mathrm{SE} \mathrm{B}=0.01, \mathrm{p}<0.001\right)$ were significant variables predicting overall cannulation rates (table 1 ).

There were higher overall cannulation rates at the postintervention stage as compared with the pre-intervention stage. Additionally, follow-up logistic regression analyses were performed for the intervention and control groups separately to examine interaction effects. Results revealed that for the control group, at post-test, the log odds of being cannulated increased by a factor of 1.47 (table 2). However, for the intervention group, at post-test, the log odds of being cannulated decreased by a factor of 0.70 (table 2 ).

\section{Observation of cannulation technique}

Paramedics in both intervention and control areas were correctly able to identify indications for cannulation (table 3). Clinicians in the intervention area were significantly less likely to cite "because the admitting staff expect it" as an indication (5.9\% vs $32.0 \%)$. However, paramedics in the intervention area were more likely to cite "on the way to hospital to save time" (76.5\% vs. $34.0 \%)$ as an indication for cannulation. Paramedics in the intervention area were significantly more likely to clean 
Table 1 Summary of logistic regression analysis for variables predicting overall cannulation rates and inappropriate cannulation

\begin{tabular}{|c|c|c|c|c|c|c|}
\hline \multirow[b]{2}{*}{ Predictor variable } & \multirow[b]{2}{*}{ B } & \multirow[b]{2}{*}{ SE B } & \multirow[b]{2}{*}{$e^{B}$} & \multirow[b]{2}{*}{$\operatorname{Exp}(B)$} & \multicolumn{2}{|c|}{$95 \% \mathrm{CI}$ for $\exp (\mathrm{B})$} \\
\hline & & & & & Lower & Upper \\
\hline \multicolumn{7}{|l|}{$\begin{array}{l}\text { Inappropriate cannulation } \\
\text { rate }\end{array}$} \\
\hline Site & 15.78 & 1467.74 & 0.00 & 7096427 & 0.00 & \\
\hline Timing of testing & 33.30 & 2935.48 & 0.00 & $3 \mathrm{E}+014$ & 0.00 & \\
\hline Site $\times$ timing of testing & -0.67 & 58.71 & 0.00 & 0.51 & 0.00 & $4.8 \mathrm{E}+049$ \\
\hline Constant & -3.63 & 0.48 & $57.53^{* *}$ & 0.03 & & \\
\hline$\chi^{2}$ & & $34.03^{* *}$ & & & & \\
\hline df & & 3 & & & & \\
\hline \multicolumn{7}{|l|}{ Overall cannulation rate } \\
\hline Site & 0.27 & 0.36 & 0.54 & 1.31 & 0.64 & 2.66 \\
\hline Timing of testing & 1.88 & 0.55 & $11.73^{* *}$ & 6.52 & 2.23 & 19.05 \\
\hline Site $\times$ timing of testing & -0.03 & 0.01 & $10.15^{* *}$ & 0.97 & 0.95 & 0.99 \\
\hline Constant & -2.22 & 0.21 & 108.20 & 0.11 & & \\
\hline$\chi^{2}$ & & $73.19 * *$ & & & & \\
\hline df & & 3 & & & & \\
\hline
\end{tabular}

their hands (74.5\% vs $14.9 \%$ ) before cannulation (table 4$)$. However, they were also more likely to repalpate the vein without due attention to aseptic technique (70.6\% vs $96.0 \%)$.

\section{DISCUSSION}

An educational intervention provided to clinical team leaders resulted in a non-significant reduction in inappropriate cannulation rates. The intervention did lead to a reduction in overall cannulation rates, and there was evidence of better aseptic technique in the intervention area post-intervention. Some elements of knowledge about indications and technique were worse in the intervention area. PTLs had some effect as a means of cascading key education and training in a geographically dispersed health area.

This was a quasi-experimental study with potential biases from the non-equivalent group design. ${ }^{11}$ These included selection bias from non-random selection of intervention and control groups or areas and confounding from possible other external influences on outcomes occurring between the pre-intervention and post-intervention phases and possible existing differences between areas in cannulation technique. Biases such as regression to the mean would be less likely, given that the baseline rate of cannulation was greater in the control than the intervention area and baseline differences in cannulation rates were adjusted for in the analysis. We were unable to account for differences in secular trends in the intervention or control areas in the analysis. Measurement of outcomes was unchanged and consistent before and after the intervention. The post-intervention assessment was not blinded, which was another potential source of bias.

Other investigators have used non-randomised designs in prehospital settings in studies of prehospital cardiac arrest. ${ }^{15} 16$ Similar designs have been used in primary care, particularly in quality improvement programmes or where it is technically difficult, inappropriate or unethical to randomise patients. ${ }^{17-20}$

Although cannulation rates were higher at baseline in Lincolnshire ${ }^{8}$ compared with previously published rates in London, ${ }^{2}$ other prospective studies-for example, in Scotland, have shown a gradual reduction in cannulation rates over time. ${ }^{21}$ Changes in rates of cannulation are likely to be affected by changing evidence and consensus on use of drugs and fluids in prehospital settings, whether for trauma or medical emergencies. ${ }^{22}$

Rates of inappropriate cannulation were reduced in the intervention area, but this reduction was not statistically significant.

Table 2 Summary of logistic regression analysis for variables predicting overall cannulation rates for the control and intervention groups

\begin{tabular}{|c|c|c|c|c|c|c|}
\hline \multirow[b]{2}{*}{ Predictor variable } & \multirow[b]{2}{*}{ B } & \multirow[b]{2}{*}{ SE B } & \multirow[b]{2}{*}{$\mathbf{e}^{\mathrm{B}}$} & \multirow[b]{2}{*}{$\operatorname{Exp}(B)$} & \multicolumn{2}{|c|}{$95 \% \mathrm{Cl}$ for $\exp (\mathrm{B})$} \\
\hline & & & & & Lower & Upper \\
\hline \multicolumn{7}{|l|}{ Control group } \\
\hline \multicolumn{7}{|c|}{ Overall cannulation rate } \\
\hline Timing of testing & 0.39 & 0.13 & $9.19 * *$ & 1.47 & 1.15 & 1.90 \\
\hline Constant & -2.22 & 0.21 & $108.20^{* * *}$ & 0.11 & & \\
\hline$\chi^{2}$ & & $9.33^{* *}$ & & & & \\
\hline $\mathrm{df}$ & & 1 & & & & \\
\hline \multicolumn{7}{|l|}{ Intervention group } \\
\hline \multicolumn{7}{|c|}{ Overall cannulation rate } \\
\hline Timing of testing & -0.36 & 0.20 & $3.32^{*}$ & 0.70 & 0.48 & 1.03 \\
\hline Constant & -1.95 & 0.29 & $43.96^{* * *}$ & 0.14 & & \\
\hline$\chi^{2}$ & & $3.36^{*}$ & & & & \\
\hline df & & 1 & & & & \\
\hline
\end{tabular}


Table 3 Responses on indication for cannulation

\begin{tabular}{|c|c|c|c|}
\hline \multirow[b]{2}{*}{ Indication for cannulation } & \multicolumn{2}{|l|}{ Performance } & \multirow[b]{2}{*}{$\chi^{2}$ (p value) } \\
\hline & $\begin{array}{l}\text { Intervention site } \\
\text { n (\%) }\end{array}$ & $\begin{array}{l}\text { Control site } \\
\text { n (\%) }\end{array}$ & \\
\hline \multicolumn{4}{|c|}{ Patient needs fluid replacement } \\
\hline Yes & $51(100.0)$ & $50(100.0)$ & \multirow{3}{*}{-} \\
\hline No & $0(0.0)$ & $0(0.0)$ & \\
\hline Not sure & $0(0.0)$ & $0(0.0)$ & \\
\hline \multicolumn{4}{|c|}{ Patient needs intravenous medication } \\
\hline Yes & $51(100.0)$ & $50(100.0)$ & \multirow{3}{*}{-} \\
\hline No & $0(0.0)$ & $0(0.0)$ & \\
\hline Not sure & $0(0.0)$ & $0(0.0)$ & \\
\hline \multicolumn{4}{|l|}{ Patient's condition required it } \\
\hline Yes & $50(98.0)$ & $50(100.0)$ & \multirow{3}{*}{0.99} \\
\hline No & $1(2.0)$ & $0(0.0)$ & \\
\hline Not sure & $0(0.0)$ & $0(0.0)$ & \\
\hline \multicolumn{4}{|c|}{ Admitting hospital staff expect it } \\
\hline Yes & $3(5.9)$ & $16(32.0)$ & \multirow{3}{*}{0.001} \\
\hline No & $42(82.4)$ & $33(66.0)$ & \\
\hline Not sure & $6(11.8)$ & $1(2.0)$ & \\
\hline \multicolumn{4}{|l|}{ To retain skill/practice } \\
\hline Yes & $1(2.0)$ & $5(10.0)$ & \multirow{3}{*}{0.058} \\
\hline No & 47 (92.2) & $45(90.0)$ & \\
\hline Not sure & $3(5.9)$ & $0(0.0)$ & \\
\hline \multicolumn{4}{|c|}{ On the way to hospital, to save time } \\
\hline Yes & $39(76.5)$ & $17(34.0)$ & \multirow{3}{*}{$<0.001$} \\
\hline No & $4(7.8)$ & $29(58.0)$ & \\
\hline Not sure & $8(15.7)$ & $4(8.0)$ & \\
\hline
\end{tabular}

Table 4 Observation of cannulation technique

\begin{tabular}{|c|c|c|c|}
\hline \multirow[b]{2}{*}{ Criterion } & \multicolumn{2}{|l|}{ Performance } & \multirow[b]{2}{*}{$\chi^{2}$ (p value) } \\
\hline & $\begin{array}{l}\text { Intervention site } \\
\text { ( } \mathrm{n}=51) \\
\mathrm{n}(\%)\end{array}$ & $\begin{array}{l}\text { Comparison site } \\
(\mathrm{n}=50) \\
n(\%)\end{array}$ & \\
\hline Procedure explained to patient and adequately consented & $46(90.2)$ & $38(76.0)$ & 0.0057 \\
\hline Equipment collected together in preparation for cannulation & $50(98.0)$ & $49(98.0)$ & 0.99 \\
\hline Hands cleaned with alcohol or other & $38(74.5)$ & $7(14.9)$ & $<0.001^{*}$ \\
\hline Equipment prepared by taking care to avoid contamination & $50(98.0)$ & $50(100.0)$ & 0.32 \\
\hline Patient's skin prepared and allowed to dry & $51(100.0)$ & $50(100.0)$ & - \\
\hline Tourniquet correctly applied & $50(98.0)$ & $48(96.0)$ & 0.55 \\
\hline $\begin{array}{l}\text { No repalpation or if repalpated, hands recleaned and clean pair } \\
\text { of gloves worn }\end{array}$ & $36(70.6)$ & $48(96.0)$ & $0.001^{*}$ \\
\hline Most distal site chosen for the first attempt & $42(82.4)$ & $48(96.0)$ & 0.028 \\
\hline Site suitable for the cannula not to be dislodged & $47(92.2)$ & $50(100.0)$ & 0.043 \\
\hline $\begin{array}{l}\text { Site suitable for easily cleaning of the skin (minimise } \\
\text { contamination) }\end{array}$ & $47(92.2)$ & $50(100.0)$ & 0.043 \\
\hline Vein chosen suitable for the relevant treatment required & $48(94.1)$ & $50(100.0)$ & 0.082 \\
\hline Cannula inspected for any faults & $36(70.6)$ & $34(68.0)$ & 0.78 \\
\hline $\begin{array}{l}\text { Vein stabilised and not contaminating the area where the needle } \\
\text { would be inserted }\end{array}$ & $51(100.0)$ & $50(100.0)$ & - \\
\hline $\begin{array}{l}\text { Cannula positioned, placing on the vein, inserted at the selected } \\
\text { angle and waited for the first flash back of blood }\end{array}$ & $50(98.0)$ & $50(100.0)$ & 0.32 \\
\hline $\begin{array}{l}\text { Device levelled by decreasing the angle and advancing the } \\
\text { cannula to ensure entry into the vein }\end{array}$ & $48(94.1)$ & $50(100.0)$ & 0.082 \\
\hline $\begin{array}{l}\text { Needle withdrawn until a second flashback of blood along with } \\
\text { the shaft of the cannula was seen }\end{array}$ & $49(96.1)$ & $50(100.0)$ & 0.16 \\
\hline One attempt at cannulation only & $42(82.4)$ & $46(92.0)$ & 0.15 \\
\hline $\begin{array}{l}\text { Tourniquet released, applying pressure to the vein above the } \\
\text { cannula tip when removing the needle }\end{array}$ & $50(98.0)$ & $50(100.0)$ & 0.32 \\
\hline $\begin{array}{l}\text { Cannula flushed with } 0.9 \% \text { sodium chloride to ensure patency, } \\
\text { observing for signs of swelling, leakage or any pain }\end{array}$ & $51(100.0)$ & $50(100.0)$ & - \\
\hline Sharps disposed in a sharps bin & $51(100.0)$ & $50(100.0)$ & - \\
\hline
\end{tabular}

${ }^{*} \leqslant 0.001$. 
This may have been partly because rates were very low at baseline and because the evaluation did not have sufficient power to show an effect. A previous study by Snooks et al ${ }^{2}$ also found low rates of inappropriate cannulation when this was determined by clinical consensus. However, rates of inappropriate cannulation were higher in this previous study and there was poor inter-rater reliability of what constituted inappropriate cannulation, hence our rather narrower and arguably more reliable definition, that is, inappropriate cannulation was that associated with no IV administration of drugs or fluids.

Importantly, paramedic (clinical) team leaders were used as the conduit for spreading quality improvement, ${ }^{23}$ and this method was considered to be particularly appropriate for diffusion in our geographically dispersed and large organisation.

This study demonstrates the potential for education that is cascaded through PTLs to improve aspects of clinical care in the prehospital setting. Future studies could use more robust evaluations using rigorous techniques for reinforcement of existing guidance or implementation of new health technologies in prehospital settings.

Acknowledgements: We would like to acknowledge the support of paramedics who completed the questionnaire and the managers who supported the study. In particular, we would like to thank Mark Stafford for administering the questionnaires and assessments and Deborah Shaw for her comments on the paper. A poster presentation of this study (Prehospital Intravenous Cannulation: Reducing the Risks and Rate of Inappropriate Venous Access by Paramedics) by lqbal et al won the Zoll International Prize at the "What's New in Prehospital Research", East Midlands Conference Centre, Nottingham, 26 November 2008.

Funding: This study was funded as part of an educational initiative and evaluation by the NHS East Midlands (East Midlands Strategic Health Authority).

Competing interests: None.

Ethics approval: That this was an evaluation was agreed by Lincolnshire Teaching PCT Research and Development subgroup, which oversees primary and prehospital research in Lincolnshire. Research ethics (National Research Ethics Service) approval was, therefore, not deemed necessary. Approval for Research Management and Governance was sought and gained from East Midlands Ambulance NHS Trust. The study was approved by the ethics committee of the Centre for Clinical and Academic Workforce Innovation, University of Lincoln.

Provenance and peer review: Not commissioned; externally peer reviewed.

\section{REFERENCES}

1. Halter M, Lees-Mlanga S, Snooks $H$, et al. Out-of-hospital intravenous cannulation: the perspective of patients treated by London Ambulance Service paramedics. Acad Emerg Med 2000; 7:127-33.
2. Snooks H, Halter M, Lees-Mlanga $S$, et al. Appropriateness of intravenous cannulation by paramedics: a London study. Prehosp Emerg Care 2000;4:156-63.

3. Bregenzer T, Conen D, Sakmann P, et al. Is routine replacement of peripheral intravenous catheters necessary? Arch Intern Med 1998;158:151-6.

4. Carr BG, Brachet T, David G, et al. The time cost of prehospital intubation and intravenous access in trauma patients. Prehosp Emerg Care 2008;12:327-32.

5. Zarate L, Mandleco B, Wilshaw R, et al. Peripheral intravenous catheters started in prehospital and emergency department settings. J Trauma Nurs 2008;15:47-52.

6. Levine R, Spaite DW, Valenzuela TD, et al. Comparison of clinically significant infection rates among prehospital-versus in-hospital-initiated I.V. lines. Ann Emerg Med 1995;25:502-6.

7. Pujol M, Hornero A, Saballs M, et al. Clinical epidemiology and outcomes of peripheral venous catheter-related bloodstream infections at a university-affiliated hospital. J Hosp Infect 2007;67:22-9.

8. Siriwardena AN, Iqbal M, Shaw D, et al. To cannulate or not to cannulate? Variation, appropriateness and potential for reduction in cannulation rates by ambulance staff [conference abstract]. Emerg Med J 2008;25:e1.

9. Snooks H, Halter M, Lees-Mlanga S, et al. Appropriateness of intravenous cannulation by paramedics: a London study. Prehosp Emerg Care 2000;4:156-63.

10. Soifer NE, Borzak S, Edlin BR, et al. Prevention of peripheral venous catheter complications with an intravenous therapy team: a randomized controlled trial. Arch Intern Med 1998;158:473-7.

11. Ukoumunne $\mathbf{O C}$, Gulliford MC, Chinn S, et al. Methods for evaluating area-wide and organisation-based interventions in health and healthcare: a systematic review. Health Technol Assess 1999;3:27-32.

12. Siriwardena AN. Experimental methods in health research. In: Saks M, Allsop J, eds. Researching health: qualitative, quantitative, and mixed methods. Los Angeles, CA: Sage, 2007:246-64.

13. Joint Royal Colleges Ambulance Liaison Committee, Ambulance Service Association. UK ambulance service clinical practice guidelines. London, UK: Ambulance Service Association, 2006.

14. Norusis MJ. SPSS 14.0 guide to data analysis. Upper Saddle River, NJ: Prentice Hall, 2006.

15. Hillis $\mathbf{M}$, Sinclair D, Butler G, et al. Prehospital cardiac arrest survival and neurologic recovery. J Emerg Med 1993;11:245-52.

16. Kramer-Johansen J, Wik L, Steen PA. Advanced cardiac life support before and after tracheal intubation - direct measurements of quality. Resuscitation 2006;68:61-9.

17. Harms LM, Schellevis FG, van Eijk JT, et al. Cardiovascular morbidity and mortality among hypertensive patients in general practice: the evaluation of long-term systematic management. J Clin Epidemiol 1997;50:779-86.

18. Jans MP, Schellevis FG, Le Coq EM, et al. Health outcomes of asthma and COPD patients: the evaluation of a project to implement guidelines in general practice. Int J Qual Health Care 2001;13:17-25.

19. McCulloch P, Brown P, Martin B, et al. The effects of an awareness-raising program for patients and primary care physicians on the early detection of gastro-oesophageal cancer. Surgery 2003;133:154-61.

20. Rosemann T, Hermann K, Miksch A, et al. The PAMINO-project: evaluating a primary care-based educational program to improve the quality of life of palliative patients. BMC Palliat Care 2007;6:5.

21. Graham CA, Kumaravel M, Stevenson J. Ambulance paramedic activities in North Ayrshire: a five-year review. Eur J Emerg Med 2003;10:279-82.

22. Dretzke J, Sandercock J, Bayliss S, et al. Clinical effectiveness and costeffectiveness of prehospital intravenous fluids in trauma patients. Health Technol Assess 2004;8:iii1-103.

23. Siriwardena AN. Releasing the potential of health services: translating clinical leadership into healthcare quality improvement. Qual Prim Care 2006;14:128. 